\title{
Carbonylative Suzuki-Miyaura Coupling Reactions of Aryl lodides with Readily Available Polymer-Immobilized Palladium Nanoparticles
}

\author{
Tomohiro Yasukawa* \\ Zhiyuan Zhu \\ Yasuhiro Yamashita \\ Shu Kobayashi* (D)
}

Department of Chemistry, School of Science, The University

of Tokyo, Hongo, Bunkyo-ku, Tokyo 113-0033, Japan

t-yasukawa@chem.s.u-tokyo.ac.jp

shu_kobayshi@chem.s.u-tokyo.ac.jp

Dedicated to Professor Barry M. Trost to celebrate his great contributions to organic synthesis

Published as part of the Cluster The Power of Transition Metals: An Unending Well-Spring of New Reactivity

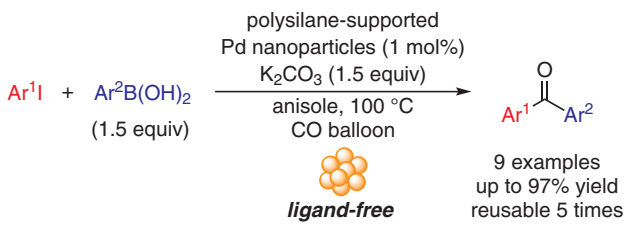

coupling reactions, the presence of an excess amount of carbon monoxide, which works as a $\pi$-acidic ligand, tends to prevent an oxidative addition process and cause metal leaching and aggregation. To address these issues, electronrich ligand moieties, such as amine, ${ }^{7}$ phosphine, ${ }^{8}$ thiol, ${ }^{9}$ and $\mathrm{N}$-heterocyclic carbene, ${ }^{10}$ have often been introduced to the support to activate and stabilize Pd species. However, tedious multistep functionalization of the support is necessary for this strategy, and nonfunctionalized carbon-supported Pd catalysts show lower activity and require highpressure conditions. ${ }^{11}$ Therefore, the development of readily accessible heterogeneous Pd catalysts with high catalytic activity and selectivity toward noncarbonylative coupling remains an important challenge. ${ }^{12}$

To convert homogeneous catalysis into the corresponding heterogeneous form, immobilization of metal nanoparticles on a solid support is of great interest because of the reusability, robustness, and high catalytic activity that such systems can offer. ${ }^{13}$ Our group developed poly(dimethyl)silane-immobilized metal nanoparticles with alumina as a second support, and the resulting catalysts have been utilized in several reactions, such as hydrogenation ${ }^{14}$ and asymmetric 1,4 -addition. ${ }^{15}$ High catalytic activity, robustness, and reusability were observed in previous reports. These supports are readily available and this catalyst (PPD100 ) itself is commercially available. Herein, we examined the use of PPD-100 and readily available polysilane $/ \mathrm{Al}_{2} \mathrm{O}_{3}$ immobilized Pd nanoparticles, in carbonylative Suzuki-Miyaura coupling reactions.

To start our investigation, we selected $p$-iodotoluene (1a) and phenylboronic acid (2a) as model substrates. The initial reaction was conducted in the presence of $\mathrm{PPh}_{3}$ using a CO gas balloon (Table 1, entry 1 ) under reported reaction 
conditions. ${ }^{16}$ The desired product could be afforded with excellent yields and the competitive Suzuki-Miyaura coupling product was only observed in a trace amount. However, a significant amount of Pd leached to the solution, which might be caused by the coordination with $\mathrm{PPh}_{3}$ ligand. Hence, a ligand-free reaction was examined (entry 2). A decreased but acceptable yield was obtained and the amount of metal leached out was dramatically suppressed. The inclusion of organic base, such as $\mathrm{Et}_{3} \mathrm{~N}$, was detrimental in terms of both yield and metal leaching (entry 3 ).

Table 1 Optimization of Reaction Conditions

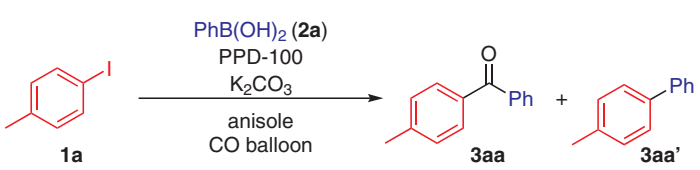

\begin{tabular}{|c|c|c|c|c|c|}
\hline Entry & PPD-100 (mol\%) & Conv. (\%) & $3 a a(\%)^{a}$ & $3 a^{\prime}(\%)^{a}$ & Pd leaching (\%) \\
\hline $1^{c, d}$ & 3 & 96 & 98 & trace & 24.7 \\
\hline $2^{c}$ & 3 & 84 & 78 & 7 & 0.3 \\
\hline $3^{c, e}$ & 3 & 58 & 20 & 0 & 15.1 \\
\hline $4^{f}$ & 1 & 95 & 74 & 21 & 0.2 \\
\hline $5^{f, g}$ & 1 & full & 95 & 7 & 0.6 \\
\hline $6^{f, g, h}$ & 1 & full & 97 & 6 & - \\
\hline $7^{\mathrm{f}, \mathrm{g}, \mathrm{i}}$ & 0.5 & full & 93 & 7 & - \\
\hline $8^{\mathrm{f}, \mathrm{g}, \mathrm{i}}$ & 0.25 & 99 & 86 & 15 & - \\
\hline
\end{tabular}

a Determined by gas chromatography (GC) analysis with 1,3,5-trimethoxybenzene as internal standard.

b Determined by inductively coupled plasma analysis of the reaction solution after filtration ('-' not determined).

${ }^{c}$ Conditions $\mathrm{A}: \mathrm{PhB}(\mathrm{OH})_{2}$ (1.1 equiv), $\mathrm{K}_{2} \mathrm{CO}_{3}$ (3.0 equiv), $0.167 \mathrm{M}$ concentration, $80^{\circ} \mathrm{C}$ for 5 hours with $0.1 \mathrm{mmol}$ scale.

${ }^{d}$ With $\mathrm{PPh}_{3}$ (3.3 mol\%).

e $\mathrm{Et}_{3} \mathrm{~N}$ was used instead of $\mathrm{K}_{2} \mathrm{CO}_{3}$.

${ }^{\mathrm{f}}$ Conditions $\mathrm{B}: \mathrm{PhB}(\mathrm{OH})_{2}$ (1.5 equiv), $\mathrm{K}_{2} \mathrm{CO}_{3}$ (1.5 equiv), $0.2 \mathrm{M}$ concentration, reacted at $100{ }^{\circ} \mathrm{C}$ for 18 hours with $0.4 \mathrm{mmol}$ scale.

${ }^{g} \mathrm{CO}$ gas was introduced into the liquid phase by bubbling from a $\mathrm{CO}$ balloon.

${ }^{\mathrm{h}}$ Reacted for 5 hours.

i Reacted for 12 hours.

After intensive screening of the reaction time, temperature, and equivalents of reagents (see Table S1 in the Supporting Information for the full entries), almost full conversion of 1a could be achieved in larger scale reactions with decreased catalyst loading and base equivalents (entry 4). However, the selectivity dropped, which might be caused by the decreased mixing efficiency between gaseous $\mathrm{CO}$ and the liquid phase with the increased reaction scale. Hence, a needle was connected to a CO gas balloon and dipped into the reaction mixture to directly introduce $\mathrm{CO}$ gas into the liquid phase by bubbling. With this modified technique, the desired product was afforded with excellent yield and selectivity without a significant amount of metal leaching (entry 5). The desired product could still be afforded with excellent yields with either shorter reaction time (entry 6) or decreased amounts of catalyst (entries 7 and 8).
To our knowledge, these are the lowest reported catalyst loadings to achieve high yield and selectivity under atmospheric pressure of CO gas (Table S2 in the Supporting Information).

With the optimized conditions in hand, a range of aryl iodides (1a-f) with different steric and electronic properties were utilized to study the generality of the developed method (Scheme 1). When the effect of substituents on the aryl ring at different positions (1a, 1b, and 1c) was examined, decreased yields and selectivities towards Suzuki-Miyaura coupling were observed in the case of ortho-substituted substrate. Both electron-deficient (1d) and electronrich (1e) aryl iodides were tolerated, affording the desired products in excellent yields. Moreover, heteroaryl iodide $\mathbf{1 f}$ was investigated, and an excellent yield could be achieved. Furthermore, the scope of the reaction with arylboronic acids 2a-d was also explored under the optimized conditions. Despite the different electronic properties, the desired products could be obtained in excellent yields while utilizing slightly modified reaction conditions.

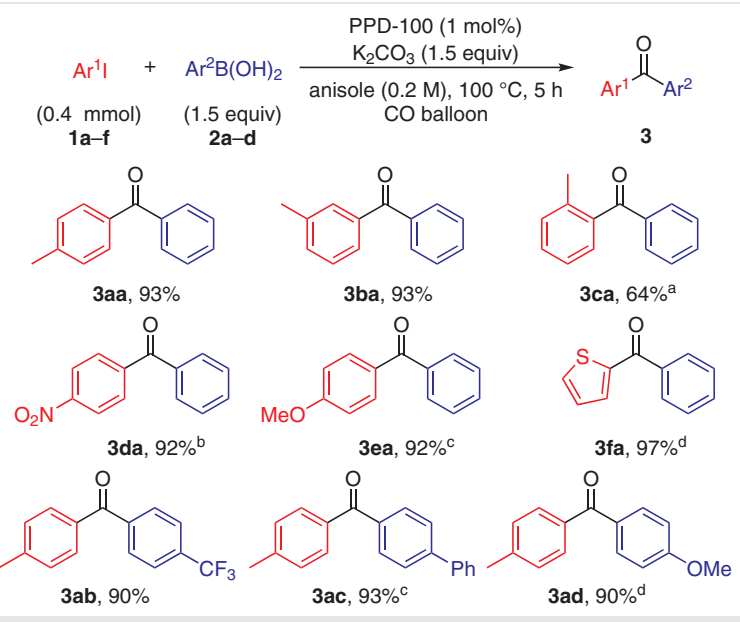

Scheme 1 Substrate scope. ${ }^{a} \mathrm{~K}_{2} \mathrm{CO}_{3}$ (1.1 equiv) was reacted for 18 hours. ${ }^{\mathrm{b}} \mathrm{K}_{2} \mathrm{CO}_{3}$ (1.1 equiv) was used. ${ }^{\mathrm{C}}$ Reacted for 8 hours. ${ }^{\mathrm{d}}$ Reacted for 12 hours.

To examine the robustness of PPD-100 catalyst towards the carbonylative Suzuki-Miyaura coupling reactions, the recovery and reuse of catalysts was conducted with the model reaction (Table 2). Upon reactivation with $\mathrm{H}_{2}$ at $100{ }^{\circ} \mathrm{C}$, the catalytic activity of PPD-100 could be maintained with a slight loss in yields within five runs.

In summary, we have developed a carbonylative SuzukiMiyaura coupling reaction with readily available PPD-100 catalyst. ${ }^{17}$ Excellent yields and selectivities could be observed for a variety of substrates under ambient pressure with low catalyst loading without using any ligands. The catalysts could be reused for several runs without significant loss in catalytic activity. 
Table 2 Recovery and Reuse of Catalysts

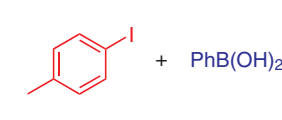

$1 \mathrm{a}$ (1.5 equiv)

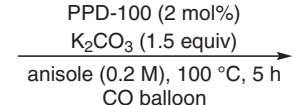
CO balloon

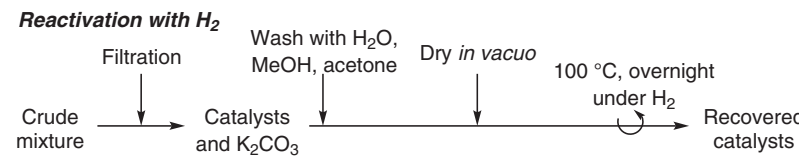

\begin{tabular}{lll}
\hline Run & Scale $(\mathrm{mmol})$ & 3aa $(\%)^{\mathrm{a}}$ \\
\hline 1 & 0.80 & 96 \\
2 & 0.79 & 94 \\
3 & 0.77 & 93 \\
4 & 0.76 & 92 \\
5 & 0.74 & 88
\end{tabular}

a Determined by GC analysis with 1,3,5-trimethoxybenzene as internal standard.

\section{Funding Information}

This work was supported in part by a Grant-in-Aid for Scientific Research from JSPS, the University of Tokyo, and MEXT (Japan), JST.

\section{Supporting Information}

Supporting information for this article is available online at https://doi.org/10.1055/s-0040-1707243.

\section{References and Notes}

(1) Surana, K.; Chaudhary, B.; Diwaker, M.; Sharma, S. MedChemComm 2018, 9, 1803.

(2) Wu, S.-B.; Long, C.; Kennelly, E. J. Nat. Prod. Rep. 2014, 31, 1158.

(3) Boscá, F.; Miranda, M. A. J. Photochem. Photobiol. B 1998, 43, 1.

(4) Gore, P. H. Chem. Rev. 1955, 55, 229.

(5) Ishiyama, T.; Kizaki, H.; Miyaura, N.; Suzuki, A. Tetrahedron Lett. 1993, 34, 7595.

(6) (a) Wu, X.-F.; Neumann, H.; Beller, M. Chem. Soc. Rev. 2011, 40, 4986. (b) Zhu, Z.; Zhang, W.; Gao, Z. Prog. Chem. 2016, 28, 1626.

(7) (a) Cai, M.; Peng, J.; Hao, W.; Ding, G. Green Chem. 2011, 13, 190. (b) Niu, J.; Xie, M.; Zhu, X.; Long, Y.; Wang, P.; Li, R.; Ma, J.J. Mol. Catal. A: Chem. 2014, 392, 247. (c) Zhu, X.; Niu, J.; Zhang, F.;
Zhou, J.; Li, X.; Ma, J. New J. Chem. 2014, 38, 4622. (d) Jiao, N.; Li, Z.; Wang, Y.; Liu, J.; Xia, C. RSC Adv. 2015, 5, 26913. (e) Long, Y.; Liang, K.; Niu, J.; Tong, X.; Yuan, B.; Ma, J. New J. Chem. 2015, 39, 2988. (f) Gautam, P.; Dhiman, M.; Polshettiwar, V.; Bhanage, B. M. Green Chem. 2016, 18, 5890. (g) Sun, X.; Zheng, Y.; Sun, L.; Lin, Q.; Su, H.; Qi, C. Nano-Struct. Nano-Objects 2016, $5,7$. (h) Zawartka, W.; Pośpiech, P.; Cypryk, M.; Trzeciak, A. M. J. Mol. Catal. A: Chem. 2016, 417, 76.

(8) (a) Cai, M.; Zheng, G.; Zha, L.; Peng, J. Eur. J. Org. Chem. 2009, 1585. (b) Wan, Y.; Song, F.; Ye, T.; Li, G.; Liu, D.; Lei, Y. Appl. Organomet. Chem. 2019, 33, e4714.

(9) (a) Niu, J.-R.; Huo, X.; Zhang, F.-W.; Wang, H.-B.; Zhao, P.; Hu, W.-Q.; Ma, J.; Li, R. ChemCatChem 2013, 5, 349. (b) Niu, J.; Liu, M.; Wang, P.; Long, Y.; Xie, M.; Li, R.; Ma, J. New J. Chem. 2014, 38, 1471.

(10) Bhanage, B.; Qureshi, Z.; Deshmukh, K.; Tambade, P. Synthesis 2011, 243.

(11) Khedkar, M. V.; Tambade, P. J.; Qureshi, Z. S.; Bhanage, B. M. Eur. J. Org. Chem. 2010, 6981.

(12) Wang, Z.-J.; Wang, X.-Y.; Wang, X.; Liang, Z.-W.; Xu, X. Catal. Commun. 2017, 101, 10.

(13) (a) Favier, I.; Pla, D.; Gómez, M. Chem. Rev. 2020, 120, 1146. (b) Cong, H.; Porco, J. A. ACS Catal. 2012, 2, 65. (c) Pla, D.; Gómez, M. ACS Catal. 2016, 6, 3537.

(14) (a) Kobayashi, S.; Okumura, M.; Akatsuka, Y.; Miyamura, H.; Ueno, M.; Oyamada, H. ChemCatChem 2015, 7, 4025. (b) Miyamura, H.; Suzuki, A.; Yasukawa, T.; Kobayashi, S. J. Am. Chem. Soc. 2018, 140, 11325.

(15) Miyamura, H.; Yasukawa, T.; Zhu, Z.; Kobayashi, S. Adv. Synth. Catal. 2020, 362, 353.

(16) Ishiyama, T.; Kizaki, H.; Hayashi, T.; Suzuki, A.; Miyaura, N. J. Org. Chem. 1998, 63, 4726.

(17) Carbonylative Suzuki-Miyaura Coupling Reaction; Typical Procedure (Table 1, Entry 6): Phenylboronic acid (73.2 mg, 0.6 mmol, 1.5 equiv), $\mathrm{K}_{2} \mathrm{CO}_{3}$ ( $82.9 \mathrm{mg}, 0.6 \mathrm{mmol}, 1.5$ equiv), and PPD-100 (40.0 mg with $0.1 \mathrm{mmol} / \mathrm{g}$ loading of Pd, $0.004 \mathrm{mmol}$, $1 \mathrm{~mol} \%$ ) were combined in a two-neck glass tube equipped with a magnetic stirring bar. $p$-Iodotoluene $(87.2 \mathrm{mg}, 0.4 \mathrm{mmol}, 1.0$ equiv) was dissolved in anisole $(2.0 \mathrm{~mL}, 0.2 \mathrm{M})$ and the resulting solution was added to the glass tube using a syringe. A balloon of carbon monoxide, equipped with rubber band and a two-way stopcock, was connected to the glass tube through a needle, and the bubbling of $\mathrm{CO}$ was started by opening the two-way stopcock. After starting to input $\mathrm{CO}$, the mixture was stirred for 5 hours at $100{ }^{\circ} \mathrm{C}$. After cooling to room temperature, the reaction mixture was diluted and washed with diethyl ether and the solid catalysts were filtrated off with a membrane filter. The mixture was concentrated, and purified with preparative TLC to afford the desired product, phenyl( $p$-tolyl)methanone, in $93 \%$ yield. 